\title{
Media as Practice: Narrative and Conceptual Approach for Qualitative Data Analysis
}

\author{
Pilar Lacasa ${ }^{1}$, Rut Martinez-Borda ${ }^{1}, \&$ Laura Mendez ${ }^{2}$ \\ ${ }^{1}$ University of Alcalá, Spain \\ ${ }^{2}$ Spain Open University, Spain \\ Correspondence: Pilar Lacasa, Faculty of Humanities, University of Alcala, Spain. E-mail: \\ placasa.uah@gmail.com
}

Received: October 5, 2013 Accepted: October 22, 2013 Available online: October 31, 2013

doi:10.11114/smc.v1i2.231 URL: http://dx.doi.org/10.11114/smc.v1i2.231

\begin{abstract}
This paper considers videogames as meaningful media in interactive and everyday contexts. In order to show our theoretical and methodological perspective for approaching media as practice, we analyze how a commercial video game, Tomb Raider: Cronicles, could be present in several scenarios. The research focuses on how to understand media in context by combining two modes of thought: the narrative, or the use of stories, and the conceptual, or the use of categorical concepts. We have adopted an ethnographical and action research perspective inspired by sociocultural psychology. Our starting point is the concept of narrative considered as an object and method of research. On the one hand, we analyze the way in which a cultural narrative, Lara Croft's story as presented in a game, is introduced in the classroom. On the other hand, we show how narratives, complemented by conceptual analysis, turn into a methodological instrument that helps to analyze the meanings that the participants attribute to the game. Our data comes from a workshop where the research team, acting as participant observers, collaborated with a teacher and her primary school students in Spain. The paper examines two levels of analysis in some detail in order to show how narrative and conceptual thinking can be combined, from a dialectical point of view, in order to understand media as tools that take part in situated activities.
\end{abstract}

Keywords: Narrative, conceptual analysis, commercial video games, new media.

\section{Introduction}

Multiple paths are open to understand how people interact with mass media. In this work we adopt the perspective of qualitative research, defined as "a situated activity that locates the observer in the world" (Denzin \& Lincoln, 2011). This paper shows how we have tried to overcome the tension between different ways of interpreting reality, dilemmas that sometimes arise when contrasting qualitative and quantitative approaches, or even different perspectives from qualitative methodologies (Lincoln, Lynham \& Guba, 2011; Tracy, 2013; Brennen, 2013; Anderson, 2012)

Bruner's ideas (2002) have served as a starting point to go beyond these contrasts, often irreconcilable. It is in this context that we try to combine conceptual and narrative ways of thinking to approach commercial videogames, considered as mediating tools of situated practices, in this case gaming in educational environments. These two forms of thinking are associated with different concepts of truth. They contrast according to their verification procedures: "One verifies by eventual appeal to procedures for establishing formal and empirical proof. The other establishes not truth, but verisimilitude (...). They function differently, as already noted, and the structure of a well-formed logical argument differs radically from that of a well-wrought story" (Kindle Edition Location 147-55). These two modes of thinking are interwoven in our approach; each provides its own way of ordering experience and constructing reality. While we take a narrative approach, we want to show how it intertwines sequentially during the research process with an analytical and conceptual approach, as both are basic tools to answer the researcher's questions and then generate new ones.

To show how intertwined these two ways of thinking are, both from the perspective of our object of study as from a methodological approach, this paper analyzes how a commercial game becomes an educational tool when introduced into a classroom to support a process of media education. This paper explores the activities of this 
multimedia educational setting, a context that allows us to talk about the media as practice. Our general aim is to show the decisions, made from a methodological approach, and to analyze the process that takes place in the classroom. The teacher and the research team collaborate to design innovative learning contexts by using a commercial video game, Tomb Raider, and turn it into an educational instrument with the idea of favouring children's acquisition of new literacies. We aim to find a methodology that helps to understand the interaction of the environment, which now includes a commercial game, with the gamers, both students and teachers who attribute specific meanings depending on the context of the game, which in this case happens to be the school.

\subsection{Objectives}

Ethnographic research begins with one or several questions that guide the work. These questions may change or be modified, and new questions may be formulated taking the initial ones as a starting point. The research goals are generated from these, which are the following in this case:

Determining how, from a methodological perspective, two approaches (analysis and narrative interpretation) can be combined.

Analyzing the meaning that a commercial video game takes for participants in the context of the game (a classroom) in which participants interact in a formal educational setting.

Exploring how the students' interaction with the game affects the construction of their oral narratives, providing a critical approach to the narrative of the game and its rules.

The paper is organized in three parts. First, we approach the concept of narrative as object and method of the research and show how it can be complemented by a conceptual analytical approach. Secondly, we present the context of the study, the participants and the data collection process, using ethnography and action research techniques. Finally, we present the analysis of the data by combining the analytical perspective, approaching what happened, and the narrative that intends to delve into how and why these events occurred. Both data collection and analysis are an example of how, on the one hand, a conceptual approach organized around the definition of a set of categories and, on the other, a narrative perspective focusing on the interpretation of oral, written and audiovisual texts can complement each other. The final discussion summarizes the main contributions of this work from a methodological point of view.

\section{Narratives \& Analysis as Object and Tool for Research}

We adopt the concept of narrative, considered from a double perspective, as our starting point. First, we focus on specific cultural narratives as present in video games when children and adults dialogue about them in educational context. Second, we use narratives as a methodological instrument from which to penetrate the meaning of human activity. We will approach the concept of narrative that is accepted in this work:

"Whenever we discuss the meaning and function of narrative in the academic disciplines, we need to distinguish between two main aspects. On the one hand, narratives are the subject area, (...). Here, one would have to distinguish whether these disciplines find their "narrative objects" more or less ready-made or whether they themselves create these totally or at least partially. On the other hand, implicit references to narratives have sparked a growing tendency towards explicit reflection upon various aspects of narration. In conjunction with this reflection, the phenomenon of narrativity itself is thematized, and with it content- or methodology-oriented concepts of narrativity are developed within the varied frameworks of the disciplines in question". (Meuter, 2009)

That is to say, we can speak of narrative as the object of study in itself considered as a storyand as a practice that can be analyzed conceptually, when a particular methodological approach is proposed to explore this object. Figure 1 summarizes these perspectives and allows us to show the theoretical and methodological framework that serves as a reference, explained in more detail in the following pages.

Figure 1 shows three levels of approach to the research, organized from the closest to reality and data to the epistemological models in which we rely. Moreover, both the object of study and the methodological tools from which we approach that object, conceptual analysis and interpreting narrative are displayed in each of these levels. On level 1 (empirical approach), the object of study is related to the immediate reality, the practices of children when they interact with a commercial videogame and specific activities in which they are present mediating in a communicative situation. The conceptual analysis at that level will determine how these practices are organized; cultural ethnography along with action research, which provide techniques for data analysis, will help to understand its meaning in the school environment. On level 2, we present the theoretical models adopted in this work. Video games as texts are understood in context, from which they acquire their meaning. We'll see how these meanings can be analyzed with specific software through a system of categories. Furthermore, using 
the narrative interpretation we will see how and why these meanings are generated. The third level places us in the epistemological foundation of the research. First, the work of Bakhtin explains the many voices that are generated from video games, when present in the classroom, as a polyphonic context. In addition to this, considering the methodological tools employed, we must take into account analytical constructivism and the Bruner's approach to scientific and narrative thinking. We will now focus on each of these three levels.

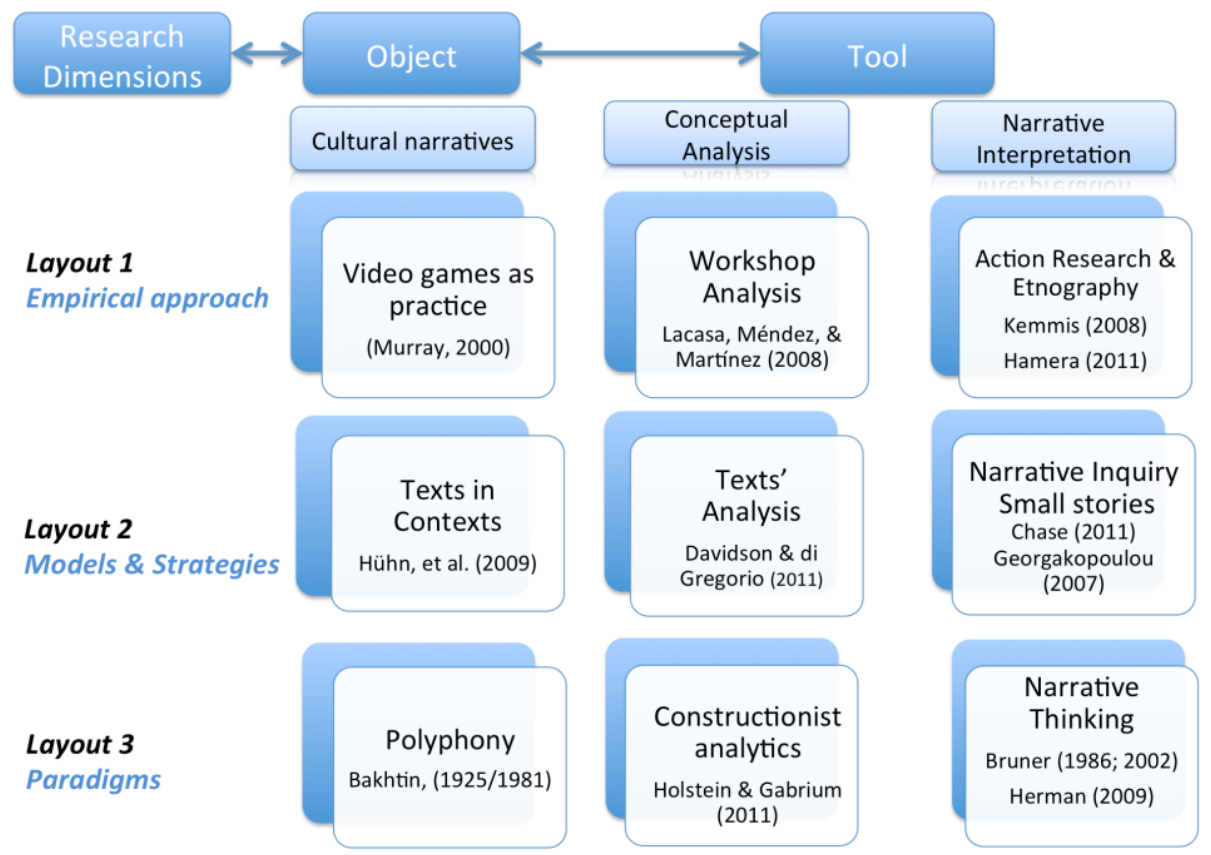

Figure 1. Narrative as the object and tool of research

\subsection{Empirical Approach to the Data}

A first approach to the data involves resembling reality. Here we explore how videogames as practice become educational tools. From this perspective, they are considered as cultural tools. According to Jesper Juul (2005), games can be explored both as objects and as activities. In both cases, the concept of rule must be taken into account: "The game as an object is a list of rules with the property that a computer or a group of players can implement unambiguously: the rules just -if implemented- produce variable and quantifiable outcomes and describe how the player(s) can exert effort." (44) From this perspective, the game is an object that raises a set of challenges. Considered as activity, "a game is a system that changes state according to a set of rules that are implemented by humans, computers or natural laws" (45); in this case the gamer comes into play: "the players are aware that some outcomes are more desirable than others."(45) In short, video games as objects generate certain responses from the players, and this possibility of interaction is what gives them their educational value.

This paper analyzes what happens in a workshop involving students, teachers and the research team at an elementary school. The main educational goal is to understand how students become aware of the processes at work in the video game and express this consciousness through specific forms of discourse. We explore the interaction with the game through oral conversations, mime and publication on a website that allows for sharing the gaming experience with other people. The ability to become aware of an activity is one of the essential features of human intelligence, and we look at this concept from the situated cognition model (Gee, 2008). This idea implies that humans learn, think and solve problems by reflecting on previous personalized experiences. In this sense, thinking and getting excited about a game requires introducing personal as well as collective experiences and becoming aware of them.

To approach these data we used techniques of ethnography and action research. It is about understanding the context where the workshops take place, that is, the school environment. Following Kemmis (2008), we adopt the concept of participatory action, a critical research perspective that seeks to integrate approaches generated by the researchers, considered as internal or external participants. That is, we seek to integrate various perspectives on the reality that also allow us to transform it with other participants, in this case students and teachers. Moreover, we adopt an ethnographical approach. According to Tedlock (p. 331, 2011), "field ethnographers, like street photographers, seek the magical in the quotidian". Hamera (2011) has also recently offered the concept of performance ethnography emphasizing the need to integrate the theoretical and methodological rationale with a 
critical theory of action embedded in practice.

\subsection{Theoretical Models and Strategies' Research}

Our second level for approaching the data focuses on the selection of theoretical models and strategies based on those models that allow us to understand how the conceptual analysis and narratives converge as the object and method of the research.

Let us look first at the object of study, videogames as practices in an educational context. Narratives and video games as practice have been a constant topic of research among those who theorize about the nature of video games as texts and even among those who design them. Considering video games, new spatial and temporal structures are present, contributing to a redefinition of narrative thinking in a way that is much closer to cinema than it is to traditional literary genres (Gee \& Hayes, 2011; Metz, 1974). However, a relation between narrative and video games is a complex topic and there are contradictory positions, such as those of ludologists, represented by Gonzalo Frasca (2004) and Jesper Juul (2005), and those of narratologists such as Marie Laure Ryan (Ryan, 2004). According to Henry Jenkins, when discussing narratives concerning video games, what is meant is that they can be lived through experiences, like those offered by films or television. This author offers a position that serves as a bridge between these two and proposes the concept of space as a dominant feature over the idea of time, traditionally associated with narrative. The spatial stories, he says, privilege the exploration of the argument and hence arises its peculiarity (Jenkins, 2006; Karnick \& Jenkins, 1995).

Now we will consider the methodological approach focusing on the theoretical models that seek to establish a complementarity between narrative analysis and interpretation. The combination of these two approaches has been argued in recent studies on methodology (Ivankova, 2013).Some years ago, Atkinson \& Delamont (2005) consider that an analytical perspective is needed. According to these authors, we need principled, systematic, and disciplined ways of accounting for the social world and to the social world. In their opinion, accounts that reduce the social world to a domain of personal experience cannot generate close and critical analyses of culture and human activity. Much more recently, perhaps with the concept of "mixed methods", it has sought to respond to these demands. Of particular interest are Denzin's contributions in this context:

"Mixed methods discourse represents a challenge to the broader qualitative interpretive community. It can be read as an invitation to rethink terms that even a decade ago were settled, from validity to design, from praxis to reform. An open mind is required." (Denzin 2010, p. 420)

In our work, we follow two perspectives closely. The first one, supported by computer resources in order to perform a conceptual analysis, focuses on what the facts tell us through the exploration, reorganization, interpretation, and integration of the research materials (data). These four components require that researchers retrieve, rethink, compare subsets, and identify patterns and relationships (Davidson \& Gregorio, 2011, p. 628). The second one focuses on the idea of narrative inquiry. According to Chase (2011), it is a sub-type of qualitative research interested in life experiences, as narrated by those who live them. Specific discourses and processes of meaning making must organize experience; activities and events could be connected sequentially. Narrative inquiry, as a research approach, allows researchers to explore and interpret the activity of individuals, cultures and societies considering a temporal perspective.

Studies that combine analysis with a conversational narrative approach have been essential in our research (Fludernik, 2009; Hollingsworth \& Dybdahl, 2007; Krippendorff, 2013). Specifically, we will explore the contributions of Georgakopoulou (2007, p. 5-6)to explore the narratives that are present in school conversations. Looking for new models for analyzing narratives, she focuses on everyday storytelling, specially "small stories":

"small stories ...can be brought together on the basis of their main characteristic, namely that they are presented as part of a trajectory of interactions rather than as a free standing, finished and self-contained unit. More specifically, a) the events they report have some kind of immediacy, i.e. they are very recent past or near future events, or are still unfolding as the story is being constructed; b) they establish and refer to links between the participants' previous and future interactions ... including their shared stories. In this way, the stories are not only heavily embedded in their immediate discourse surroundings but also in a larger history of interactions in which they are intertextually linked and available for recontextualization in various local settings" (Georgakopoulou, 2007, p.40)

These stories, present in classroom conversations between children and adults, are interesting for us. They will be our unit of analysis when we get closer to the interpretation from the perspective we call "narrative inquiry".

Summing up, considering this second dimension of research we emphasize that we look at video games as texts, acquiring their meaning from the context in which they occur. These texts include narratives; but in turn, they are 
organized according to rules that guide the activities of the gamers. To examine and determine the meaning of educational practices, we will rely on specific software to organize and browse the data; it is the tool for conceptual analysis. To explain how and why meanings are developed we will rely on interpretive research, specifically in the stories that people construct from the game, approaching the "small stories", or micro stories, interwoven in the conversations.

\subsection{Paradigms and Epistemological Approach}

Theoretical models that support this work are sustained at the same time on epistemological approaches that influence the researcher's perspective. Focusing on them, we will refer to the object and method of research, emphasizing the concept of narrative and how it can be combined with a conceptual analysis.

Looking at narratives as objects of study, built in the workshop around a commercial video game, we are interested in the epistemological model present in the work of Bakhtin (1925/1981). His contributions allow us to understand how people apprehend reality as a lived experience. Real and imaginary narratives "subjectivize" the experience, inviting the reader to reconstruct what might have happened, both opening up rather than closing possibilities. Adopting this perspective we focus on the Bakhtinian ideas to approach narratives as an object of study in relation to the fact of introducing video games into the classrooms. It is interesting to note how he established sharp contrasts between the early nineteenth century novel, which was monological in its structure, and the Dostoevsky novel characterized by polyphony in which no single voice within a narrative is the bearer of a definitive truth. The perspective of the omniscient author is silenced; the central characters are given a particular kind of autonomy through what he described as a dialogical penetration of their personalities. What this means when we consider computer games as multimodal texts, is that any one voice needs to be silenced in specific social and historical circumstances.

Moreover, epistemological models underlying our methodology focus on analysis and interpretative narratives. As regards the conceptual analysis, the work of Holstein \& Gabrium (2011 5030) has inspired our approach. The author defines his perspective as "the constructionist analytics of interpretative practice".

"The program canters on the interactional constitution of lived realities within discernible contexts of social interaction. We use the term "analytics" because the approach and its variants produce understandings of the construction process by way of distinctive vocabularies, (...) a systematically lined set of "sensitizing concepts spare enough not to overshadow the empirical, yet robust enough to reveal its constructionist distinctive contours" (p. 341-2).

This approach emphasizes the analysis of constructive action-in-context, they are interested in how and what of social reality. His goal relates to both how people methodically construct their experiences and their worlds and the contextual configurations of meaning.

Finally to see how a narrative can complement this approach, we will turn to the work of Jerome Bruner, most recently extended by Herman (2009), who prefers to emphasize complementarity between etic and emic approaches.

"Here at the outset, it is important to address a broader - indeed, foundational - issue pertaining to my attempt to identify basic elements of narrative. This issue can be approached by way of the distinction between what might be termed "etic" and "emic" approaches to narrative study - a distinction also applied by (Georgakopoulou, 2007) (...) To extrapolate from this distinction: whereas etic approaches create descriptive categories that are used by analysts to sift through patterns in linguistic data, whether or not those categories correspond to differences perceived as meaningful by users of the language being analysed, emic approaches seek to capture differences that language users themselves orient to as meaningful. Accordingly, a question for any account of the basic elements of narrative is whether those elements are in fact oriented to as basic by participants engaged in story telling practices (=emic), or whether the elements are instead part of a system for analysis imposed on the data from without (=etic)" (p. 2-3) (lo. 123)

That is, he sets up a contrast between stories and science. In his opinion, narrative is a basic human strategy for coming to terms with time, process, and change - a strategy that contrast with, but is in no way inferior to, "scientific" modes of explanation that characterize phenomena as instances of general covering laws. Science explicits the atmospheric processes that (all other things being equal) account for when precipitation will take the form of snow rather than rain; but it takes a story to convey what it was like to walk along a park trail in fresh-fallen snow as afternoon turned to evening in the late autumn. Both approaches are complementary.

Let's look at how the three dimensions of research just referred to (Figure 1), from the nearest to the farthest from reality in terms of object and method of study, are present in our work: empirical approach, strategies and 
research models and epistemological foundation.

\section{Context and Data Sources: empirical approach}

What we call empirical approach involves approaching the real and virtual context in which the data were taken to reality. We will look, therefore, at the activities that occur in a video game workshop in which students work with Lara Croft. We will see in this first level how analytical and narrative approaches intertwine from the perspective of the object and method of study. In this context, the process of data collection is part of a longitudinal and ethnographic design. The types of data that have been collected are ethnographic participants' observations, video and audio recordings and written and audiovisual documents produced in the workshop.

\subsection{Participants}

The research was conducted in a public elementary school where the research team had worked previously. One of the teachers was a student in teacher training courses at the university. The school is located in a working town near Madrid. The families of the students who participated in our study were young, about $60 \%$ aged between 36 and 45 . The level of education was low, with only $6 \%$ of them holding a college degree and between $23 \%$ and $34 \%$ split evenly between primary studies and media training. Regarding their employment situation, most parents were employees $(68.50 \%)$ and a large number of mothers were housewives (47.19\%). The students were immersed in neighborhood life. The group was very diverse, with children of 10 different nationalities, accounting for approximately $10 \%$ of the total. The school is an important point of reference for them in terms of friendships, games, sports and extracurricular activities.

\subsection{The Video Games Workshop}

We worked in a multimedia workshop in a Spanish public school; the students were in their third year of primary education (8-9 years old). The aim of the adults was to situate the children critically in front of the screens of the game, Lara Croft's Tomb Raider adventures, by means of successive reconstructions of the game and by supporting specific processes of meta-reflection. In this context, we worked for seven two-hour sessions, in which 11 boys, 10 girls and their teacher participated, as well as the researchers themselves as participant observers. All the sessions were video-recorded and we collected all the children's productions. Lastly, each of the participant observers produced daily summaries of the sessions, thus enabling multiple interpretations of the same activities to be made. Once all the data was digitized, they were examined using Atlas.ti (5.0).

Table 1. Data collected during the workshop: The workshop's activities, audio, video recordings and other materials

\begin{tabular}{|c|c|c|c|c|c|}
\hline Session & Context & Setting & Classroom activity & $\begin{array}{l}\text { Audio \& Video } \\
\text { recording }\end{array}$ & Other material \\
\hline 1 & $\begin{array}{l}\text { Ordinary classroom } \\
\text { Both individual and group } \\
\text { work (whole class) }\end{array}$ & Video game & $\begin{array}{l}\text { "My favorite videogames", } \\
\text { general discussion. } \\
\text { Voting to choose a videogame } \\
\text { Writing about "my favorite } \\
\text { videogame" }\end{array}$ & $\begin{array}{l}\text { Audio \#1-4 } \\
\text { Video \#1-2 }\end{array}$ & $\begin{array}{l}\text { Children's texts about their } \\
\text { favorite digital game. }\end{array}$ \\
\hline 2 & $\begin{array}{l}\text { Computer room } \\
\text { Small groups and whole } \\
\text { class group }\end{array}$ & & $\begin{array}{l}\text { Playing "Tomb } \quad \text { Raider } \\
\text { Chronicles" } \\
\text { Writing about the game }\end{array}$ & $\begin{array}{l}\text { Audio \#5-6 } \\
\text { Video \#3aand 3b }\end{array}$ & $\begin{array}{l}\text { Videogame: "Tomb Raider } \\
\text { Chronicles" }\end{array}$ \\
\hline 3 & $\begin{array}{l}\text { Ordinary classroom, using } \\
\text { an electronic projector } \\
\text { Small groups }\end{array}$ & & $\begin{array}{l}\text { Reading children's texts } \\
\text { Talking and writing a story about } \\
\text { Tomb Raider }\end{array}$ & $\begin{array}{l}\text { Audio \#7-9 } \\
\text { Video \#4 }\end{array}$ & $\begin{array}{l}\text { Voting ballots to choose the } \\
\text { video game }\end{array}$ \\
\hline 4 & $\begin{array}{l}\text { Ordinary classroom } \\
\text { Whole class group and } \\
\text { small groups }\end{array}$ & Performance & $\begin{array}{l}\text { Continuing the story } \\
\text { Playwriting } \\
\text { Choosing the main characters }\end{array}$ & $\begin{array}{l}\text { Audio \#10-11 } \\
\text { Video \#5 }\end{array}$ & Small groups theater' script \\
\hline 5 & $\begin{array}{l}\text { Ordinary classroom } \\
\text { Small groups and whole } \\
\text { class group }\end{array}$ & & Theatrical representation & $\begin{array}{l}\text { Audio \#12-13 } \\
\text { Video \#6 }\end{array}$ & Pictures \\
\hline 6 & $\begin{array}{l}\text { Ordinary classroom, using } \\
\text { an electronic projector } \\
\text { Whole class group }\end{array}$ & Web Site & $\begin{array}{l}\text { Looking at other children's Web } \\
\text { pages. } \\
\text { Planning their own Web pages }\end{array}$ & $\begin{array}{l}\text { Audio \#14 (Teacher } \\
\text { interview) -16 } \\
\text { Video \#7 }\end{array}$ & $\begin{array}{l}\text { Texts including main } \\
\text { conclusions for the Web } \\
\text { page }\end{array}$ \\
\hline 7 & $\begin{array}{l}\text { Computer room using an } \\
\text { electronic projector } \\
\text { Whole class group }\end{array}$ & & $\begin{array}{l}\text { Looking at their own web pages } \\
\text { prepared by the research team } \\
\text { Main conclusions }\end{array}$ & $\begin{array}{l}\text { Audio \#17 } \\
\text { Video \#8 }\end{array}$ & Web page \\
\hline
\end{tabular}


The educational goal of the workshop was to develop new literacies, related to the construction of narratives, that would be expressed through different discourses, supported by the game's story. Table 1 shows three clearly differentiated phases, all of them closely related to different forms of activity that children and adults carried out during the sessions: Playing video games, a theatrical representation related to the game and then telling other people about their workshop by posting on the school's web page. These three clearly differentiated moments are relevant from a methodological perspective. In each of them, different types of linguistic codes are present: oral discourse that mediates the relationships among participants while working in the classroom, mime through representing the play of the game and audiovisual language, present both in the game and the Web page, created in the final sessions to account for their activities through the Web. The strategies used by teachers and researchers during each session consisted of promoting the grasp of consciousness of the game through different reconstructions of the story through specific discourses: oral, written, mime and audiovisual.

\subsection{The Game: a Virtual World in the Classroom}

The video game Tomb Raider Chronicles was chosen because it was the most popular among the children. The teacher accepted their suggestions. If they normally played alone and outside the classroom, this game could become a bridge to bring the real world into the classroom and, above all, it would be possible to reflect on the world of values raised therein. Clearly, this is a violent game, but it allows us to know why most kids wanted to play with it and, above all, it leads to discussions related to value education. Mass media place children in situations of violence and it is necessary to learn and teach how to address them.

This game is the fifth in a saga in which Lara Croft is the heroine. It aims to recapitulate the best adventures experienced by the protagonist, after her death in the previous release of the game. Lara Croft is an archaeologist, and each of her adventures is cantered around the challenge to find magical artifacts. The game begins with Lara's funeral, having been buried in the 4th Tomb Raider game. Given this fact, several of her best friends come together to remember some of the most interesting adventures they lived with her: in Rome, in a submarine, in Ireland when Lara was a teenager and in a heavily guarded building. In these four scenarios is where the game develops, with Lara Croft dressed in different ways depending on the location and mission she has to accomplish. The action of the game is to climb, jump and fight in the middle of Mayan ruins and royal tombs in search of ancient relics, Indiana Jones' style. In addition to facing the enemy, countless riddles have to be solved.

In general, each stage of this saga has only one valid way to be discovered among all possible paths through a series of tests: solving puzzles (activating mechanisms or using found objects), or running away from human, animal and fantastic enemies, fleeing from specific locations by employing acrobatics and finding secret doors. These actions, which can damage Lara (i.e. shots, falls, traps, bites, burns), are reflected by a health bar. The level of health can be recovered with medical kits that Lara finds along the way but, if the damage is intensive, the health bar reaches zero, she dies and the game ends. The game can be saved at any time, so that there is no need to repeat the whole screen when one fails.

\section{Research Strategies and Results}

Understanding media in relation to the context in which they are interpreted involves defining units of analysis beyond isolated individuals and elements. In this paper, we define a unit of analysis by a segment of reality that makes sense in a given context. Is must be considered in terms of the objectives of the work and, in this case, that segment is organized around school practices, when children interact with each other, with adults and, in addition, these relationships are mediated by the game.

To understand these school practices, segmented into meaningful units in a given context, we need to consider the contributions of each participant as dependent on each other and the scenario in which they emerged. The research strategies will be defined in relation to these practices and from the proposed objectives. Let us remember that, considering analytical and narrative thinking as object and method, this paper aims to understand, on the one hand, how the students' interaction with the game affect the construction of various narratives: oral, written and audiovisual, allowing development of narrative thinking and a critical approach to the narrative of the game and its rules.

\subsection{Organizing, Reconstructing and Analyzing Data: What Happened}

The organization of data in qualitative research is already a part of the analysis. Software designed specifically to carry out this organization (e.g., software as Atlas.ti, Nudist or Transana) gives us two types of instruments: on the one hand, those which allow for the organization of documents, audiovisual or written, and on the other, those which facilitate encoding the information as it appears on these documents (Lewins \& Silver, 2007; Pink, 2012). 
In this study, the first phase of analysis began with the organization of the available documents. Figure 2 shows how an audiovisual discourse involved in classroom recordings (primary documents in Atlas.ti) is the starting point of the analysis oriented to determine what happened when commercial video games are introduced in the classroom. Other documents developed by the researcher (memos) will be added to these, and that will gradually allow an interpretation of the data.

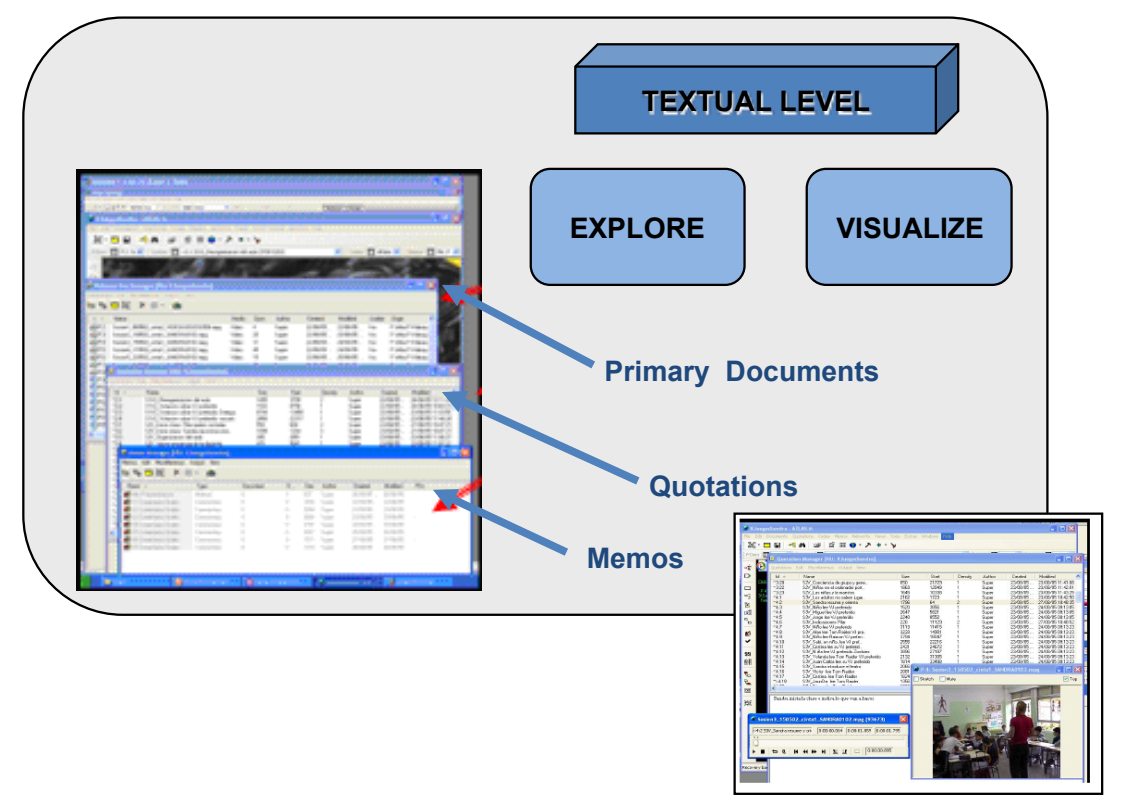

Figure 2. Organizing data

When using Atlas.ti, the analysis itself begins with the segmentation process of primary documents into fragments that make sense by themselves in the context in which they occurred. This segmentation is what generates the quotations, segments of the primary documents that make sense by themselves. In our case, these are video segments that this software analyses in terms of frames, which are identified into a time code corresponding to each of the quotations. Table 2 shows an example of how these were analyzed in the first session. We noticed that the video of the first session was segmented into quotations; here they are the first 9 quotations. Each quotation is a meaningful unit, and its temporal length is between 1 minute 2 seconds (the shortest) and 3 minutes 33 seconds (the longest). Each of them has been individually labelled to make it possible to understand what happens throughout the session. In the example shown in Table 2, and reading the names that identify each quotation, we can see that the teachers and researchers introduced the classroom activities and also pointed out the importance of going beyond gaming and entertainment situations because, besides gaming, children will be writing and exploring the game in depth. Those titles suggest that learning from the game involves going beyond automatic actions.

Table 2. Exploring children's activities using quotations

\begin{tabular}{|c|c|c|c|}
\hline FILE \& QUOTATION & $\begin{array}{l}\text { CONVERSATION CONTENTS AND CLASSROOMS } \\
\text { ACTIVITY }\end{array}$ & FRAMES & H:M:S \\
\hline Session: $1: 1$ & Researcher's long presentation & 3159 & 0:02:06 \\
\hline Session: 1 : 2 & Reading and writing on the Internet & 5346 & 0:03:34 \\
\hline Session: $1: 3$ & Several resources for presenting information & 1060 & 0:00:42 \\
\hline Session: $1: 4$ & Children and Internet & 1727 & 0:01:09 \\
\hline Session: 1 : 5 & Writing, about what? & 3483 & 0:02:19 \\
\hline Session: 1 : 6 & Video games and violence & 1575 & 0:01:03 \\
\hline Session: 1 : 7 & The teacher: thinking by using video games & 1522 & 0:01:01 \\
\hline Session: 1 : 8 & Researcher's long presentation & 4377 & 0:02:55 \\
\hline Session: 1 : 9 & Reading and writing on the Internet & 3808 & 0:02:32 \\
\hline
\end{tabular}

The information provided by the quotations can be extended with the information provided in a memo included by the researcher on this first session (Table 3). Both the theatre, related to the interest of the teacher, and the posting on the Internet proposed by the researchers as educational resources will include the use of different 
types of discourse. Both of them are associated with an awareness of the activity in different learning contexts.

Table 3. Understanding activities by using a memo

Videogames, Drama \& the Internet

Session 1

To understand them it appears to be important to bear in mind the previous conversation we had with the teacher a few days before, when we discussed how to introduce the game in the classroom. She proposed introducing the video game into the classroom at the same time that the children were involved in drama activities.

The researchers were interested in instilling values using games and the Internet as educational tools and even sought to work against violence in games, the teacher seemed to have another goal that was not clearly defined. Nor was it clear, at that moment, what the goals of the children were for the workshop.

The analysis of the activity proceeds through a process of encoding predetermined quotations. We need to find common features between segments through a process of categorizing. Figure 3 shows how Atlas.ti allows for two procedures: (a) coding and (b) linking concepts by defining networks to establish specific connections among them. What is clear is that coding enables researchers to give meaning to the data. Moreover, and beyond coding and retrieval, the Atlas.ti networking feature allows to visually "connect" selected passages, memos and codes into diagrams that graphically outline complex relations. This feature virtually transforms the text-based workspace into a graphical "playground" where we can construct concepts and theories based on relationships between codes, text passages and memos. This procedure sometimes uncovers other relationships in the data that were not obvious before but still allows for the ability to instantly revert to notes and primary text selection (Murh \& Friese, 2004).

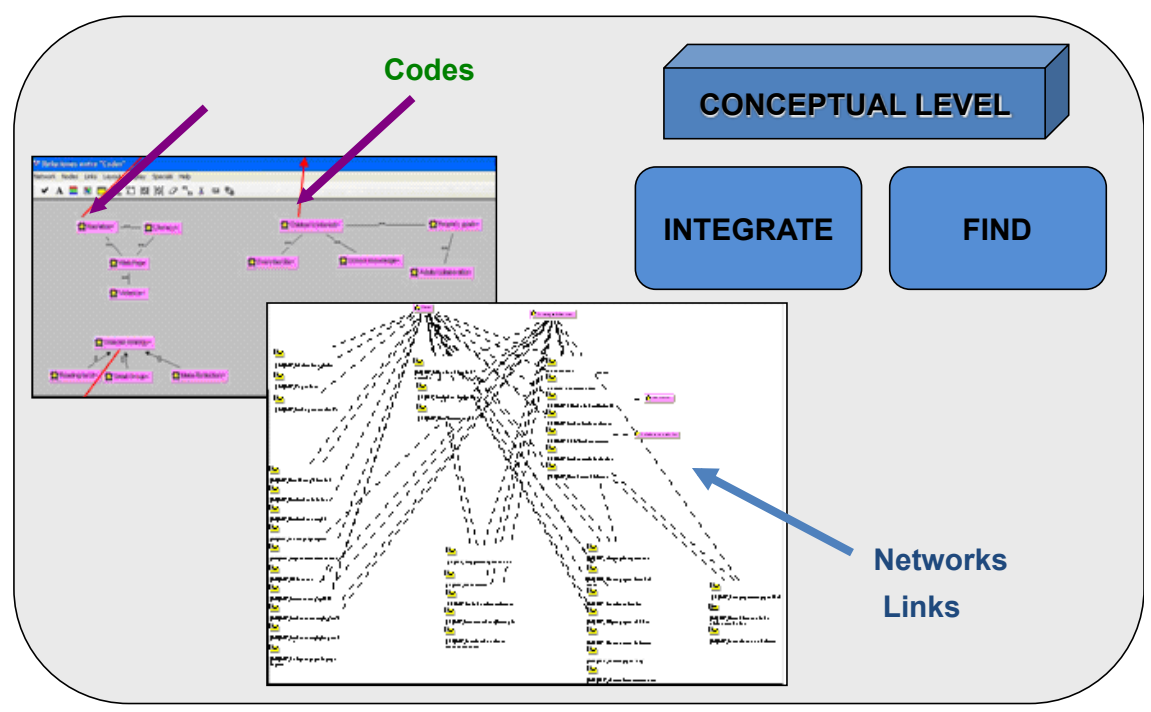

Figure 3. Conceptual levels of analysis

We now present how we carried out this level of analysis, focusing on the examples provided by several sessions allowing for the understanding of changes across time. Theory and method have to move on parallel tracks. At this level, the theoretical framework underlying the analysis of children's activities refers to the complexity of the process of representation that implies the use of specific modes of expression (Jewitt, 2009). What we have in mind is the degree of awareness possessed by the children, a degree that can be associated to a certain level of literacy (Gee, 2006). As may be observed, the contents of the conversation have been categorized according to two aspects:

- First, the conversations' content regarding the educational scenario created by adults, which is represented by a specific colour(video games, theatre) and the Internet for a better explanation of the results through a graphic system.

- Second, the action or discourse used in connection with these issues, involving different levels of awareness of the activity, different processes of representation. This is presented by the intensity of the colours used for each of the specific contents (video games, theatre). 
Table 4. Categories of analysis for approaching the videogames workshop

\begin{tabular}{lll}
\hline Content & Code/Category & Map Representation \\
\hline Games & Playing DG & Talking about DG \\
& Reading texts DG \\
& Building oral narratives DG \\
& Writing about DG \\
& Talking about theatre \\
& Preparing for theatre \\
& Writing a script \\
& Playwriting \\
& Theatre play \\
\hline Theatre & Talking about the Internet \\
& Internet \& DG \\
& Writing on the Internet \\
\hline Others & Moral education \\
Others & Adult instructions \\
\hline
\end{tabular}

That is, multimodal codes were considered as associated with specific forms and levels of representation, in relation to specific processes as present in video games (DG), theatre and the Internet. As we mentioned before, in these three different kinds of contexts, several categories were established by focusing on modalities of building meaning; for example, acting, talking, reading, writing and playing. Each specific quotation had been categorized in the sessions according to these specific codes that appear in Table4. This is a content analysis of the conversations, through the proposed category system.

Figure 4 shows a synthesis of the results, including graphs constructed from the coding procedures. The changes taking place in the process of constructing narratives from the game, using different discourses, is what appears there. Bar graphs show the time spent in relation to the different contents and levels of representation in each of the sessions. That is, the data are analyzed in terms of duration, a quantitative criterion that allows for exploring and describing what happened in the workshop, what activities were present and what levels of representation were generated.

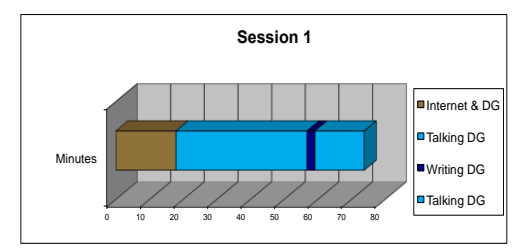

Video games enter into the classroom
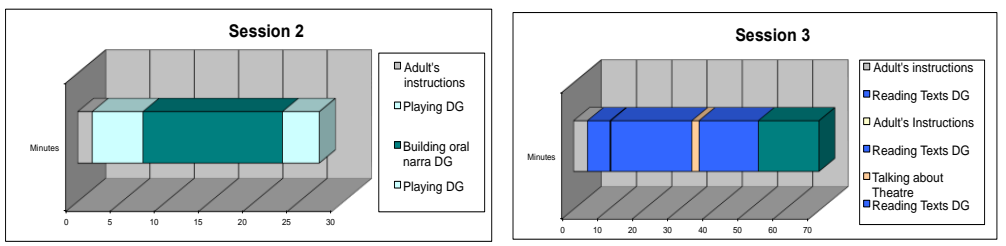

Representing a theater play
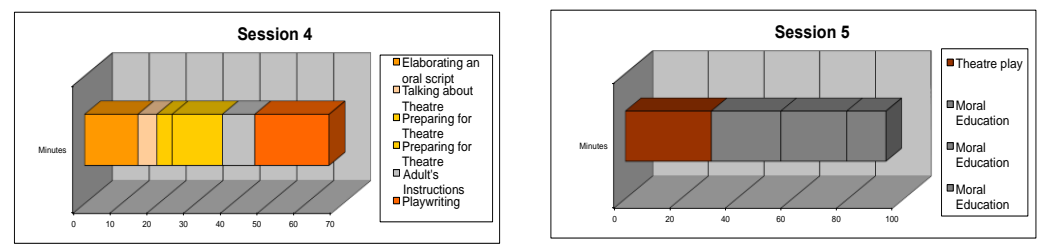

Publishing a Web page
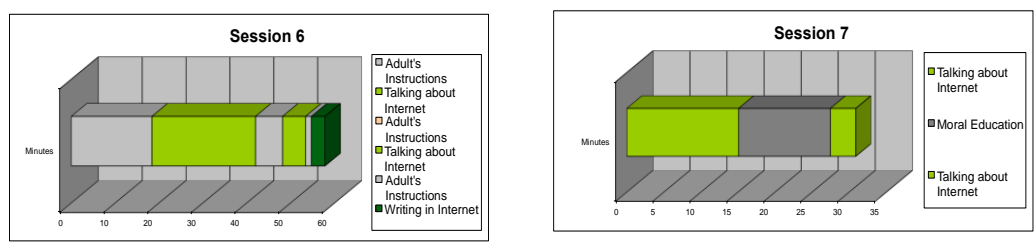

Figure 4. Building narratives using multiple discourses during the workshop

- Looking at the first three sessions of the workshop, there is a predominance of oral conversation whose main topic was the game. For example, during the first session 33 minutes of a total of 74 were dedicated to discussing this content. Children mentioned what were their favorite games. The construction 
of stories from the video game was the task proposed in the second session; 16 minutes are dedicated to it from a total of 37 . The third session focuses on reading texts that children had prepared at home, 48 minutes out of 70 minutes, and 17 minutes to the new oral versions of the story.

- A performance the children had to prepare based on the videogame was the focus of Sessions 4 and 5 . In Session 4, 15 minutes were dedicated to a new oral reconstruction of the story and 20 minutes to write the script for the theatre performance in small group situations. Session 5 includes the theatrical performance for 31 minutes and then they have a discussion centered on the issue of violence. This can be interpreted as a meta-reflection process supported by adults, a process of values education in relation to media messages.

- Sessions 6 and 7 focus on the preparation of a web page to show other children how they had worked in the workshop. Again, it involves the use of other forms of discourse. Much of the time they talked about the Internet ( 24 minutes in the first session and 15 minutes in the second). Also, a discussion about moral values took place there (12 minutes during the second session). It is interesting to note, moreover, the presence of very long interventions from the adults (for example, 25 minutes during Session 5).

What conclusions can be drawn from this first analysis of the data, considering the objectives of the paper? Let us remember that this work aims to show, from a methodological perspective, how analysis and narrative are both subjects and research methods. We examine the processes through which children construct narratives in different contexts, mediated by commercial video games, and how the presence of the media in the classroom can foster the development of narrative thought. Data express what happens during the workshop. Four conclusions can be generated from a conceptual analytical approach from these data. First, regarding the content of the talks in scenarios created to facilitate the construction of narratives, it is observed that oral language plays an important role. The game is discussed before beginning the construction of the narrative itself. It is a good educational strategy, although narrative is usually learned in writing and without excessive preliminaries, at least in Spanish schools. Second, the data also show that the teachers and researchers took the time to develop oral histories, which were obtained in different versions at several times throughout the workshop. Third, it highlights something we did not anticipate: the time devoted to the discussion of issues backing moral education. Finally, we shall point out the presence of instructions from the adults, especially relevant for the time dedicated to them during the session that introduces the preparation of a Web page. We will go deeper into the above data, obtained from a conceptual analysis, when we use a narrative approach, as discussed in the initial plan of this paper.

\subsection{How and Why did It Happen? The Narrative Interpretation}

At this time, we consider narrative as a way of understanding one's own and others' processes of organizing events and objects into a meaningful whole, connecting and seeing the consequences of actions and events over time. Herman (2009) notes the following basic elements in a narrative:

"Stories can be analyzed into four basic elements, some with sub-elements of their own. I characterize narrative as (i) a mode of representation that is situated in - must be interpreted in light of - a specific discourse context or occasion for telling. This mode of representation (ii) focuses on a structured time course of particularized events represented are (iii) such they introduce some sort of disruption or disequilibrium on the storyboard, whether that world is presented in actual of fictional, realistic or fantastic, remembered or dreamed, etc. The representation also (iv) conveys what it is like to live through this story world-in-flux, highlighting the pressure of events on real or imagined consciousness undergoing the disruptive experience at issue. As noted previously, for convenience of exposition these elements can be abbreviated as (1) situatedness. (ii) event sequencing”, (iii) word making/world disruption, and (iv) what it's like" (pos. 227)

These four dimensions are present in school conversations, and we consider them as a source of data to be interpreted. We take as a starting point the notion small narratives present in conversations suggested by Georgakopoulou (2007) and to which we have referred above. Considering our objectives, we will go deeper into how and why events occurred in the workshop and we will look for the meaning that the game acquired for the participants and what its value is as an educational tool to facilitate the construction of narratives.

\subsubsection{The Meaning of the Game for the Participants}

Why use video games in the classroom?

In the first session, the children discussed and wrote about video games. The transcript, which we include below, shows the teacher's introduction. The four dimensions that Herman (2009) points at for a text to be considered a narrative are present there. First, the teacher introduces the context, a shared experience that is related to a 
dialogue about free time (1), thence the goal of the workshop is introduced (3): "let's think about games" (1, 3). Furthermore, the presence of different verb forms becomes evident: while the teacher uses the past and the future, the researcher uses the present. Narrative is the framework in which goals are posed by the participants in the workshop.

Transcript 1. Narrative and memory in the classroom: the goal of the workshop (Session 1)

1. Teacher: Do you remember when I interviewed you, many months ago (...) about what you did during your free time? Do you remember? I wondered what you did in your free time and you told me that you played with the PlayStation and video games a lot of time

2. Children make comments among themselves and to the teacher. There is some excitement in the classroom

3. Teacher: But now, not only will we play. No, LET'S THINK about games

4. Invs. Pral: That's the key, that's the key

This micro conversational narrative helps us to understand the goal of the teacher and what it means for her to introduce video games in the classroom. We have gone beyond purely quantitative data, we see that the teacher wants to teach children how to think from the game.

\subsubsection{The Video Game Story and Its Oral Reconstruction}

The first two sessions focused on the reconstruction of the oral story, sometimes supported by written reconstructions. We will see how the teacher tries to help to reconstruct the written story of the game. Narratives are both method and object in this paper. An example:

Transcript 2. Starting to create characters (Session 2)

Teacher: During these five minutes you are going to be playing. But look, <look what the game is, who the character is $>$, what you are doing, what the places she's going to are, ++ WHY? ++ Because in five minutes ++ WE will tell everybody about the game, and + then ++ think about all we are doing TO TELL <OTHER KIDS>: remember that we will write on a web page, so that other people ++ will also be aware of what we are doing here ++ right?

This previous transcription includes elements that, according to Herman (2009), have to be present in a narrative. Let see the context: the teacher introduces the performance. She encourages children to focus on their actions on the game. It is the first feature of this micro story. Furthermore, by using different tenses, she presents a succession of activities. These rely on the characters and what happens in the game. The presence of disequilibria that contribute to the creation of new representations of the world is given, perhaps, by the allusion to the website, where kids post their experience. In this case, the teacher is helping to understand the game as something shared via the Internet. After some time playing, the construction of the narrative begins. The teacher gives clear instructions: we must look at which characters appear and what happens in the game (1). From there, the story begins to be rebuilt. The researcher will be writing down the ideas suggested by the children on the board.

1. Child: Sandra, the game is about a girl whose father was killed and then she's going around and she is killing tigers, birds, :::::>

2. Teacher: That's it, she is a girl whose parents have been killed and she's going around $++++::$ : KILLING

3. Child: and she takes revenge

4. Teacher: And she takes revenge, but we will see, to avenge the killing of their parents, what is she looking for?

5. Child: Well ::: killing all the tigers = AND BROWSING THE EYE

6. Child. The eye of the triangle

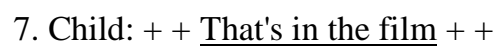

We have seen how a micro story, which in this case concerns the story of the game and has been consciously rebuilt by the speakers, indicates that the children learn to tell by looking at the game's protagonist and her actions. Children are more interested in actions than in the locations in which actions occur.

4.2.3 The Awareness of the Game in the Development of the Story: writing and performing

What is the role of written texts to generate stories about the game? 
Whereas the oral story took a more important role in the first two sessions, now it will be the written text's turn. Again, we understand it through the micro story presented in the conversation and, especially, by the instructions of the teacher.

Transcript 3. The teacher summarizes the previous sessions (Session 3)

Teacher: Look (.) < Remember the other day we were watching different video games $><$ you talked about them $>=++$ We selected one of them, we voted and <Tomb Raider > won $++()+$.+ Then we were watching Tomb Raider ++ in the computer room $=$ then you were playing, (.) right? We all were discussing that. Well, look $=++$ I have your work, your WRITINGS + + <and your drawings> (.) / / What do we do now? Well, one by one, you are going to read it aloud and you are going to show it to your partner $=$ OK? So that we know all ++ THAT WE'VE WRITTEN ++ and what is what we have drawn.

This time, the teacher is once again leading the session, reminding the children what they did at the previous meeting and especially focusing on their work. Moreover, she is organizing the following task. The teacher proposes to read the childrens' work and to show their drawings. She creates a situation of very enriching dialogue, where ideas are valued and shared with all the workshop participants. The use of written language will reinforce the actions and characters that appeared in the context of the conversation.

\section{The story of the game in the theatrical performance}

A simple narrative, constructed by the teacher by mentioning three successive activities, again points at the context of the task. She will hand out a piece of paper, because they will write a theater play, which involves inventing. The introduction of the notion of inventing involves disequilibrium in the representation of the world.

Transcript 4. Writing the plot in small groups (Session 4)

1. Teacher: Okay, ++ Look ++ Now $++\underline{+}$ 'll distribute a piece of paper +++ (.) Sil...silence) $::$

2. Teacher ++ Let's see,++ I will distribute <one sheet>to each representative of the groups and what are we going to have to do? $>++$ Write the play together, invent. ++ What are we going to do? + + We invent, okay? There(.)

Table 5 includes the script written by one of the groups and a description of the performance. The script is a sequence of actions that represents and clearly indicates the activity of each character, which is also marked with the number assigned to the actor or actors and the name of the children.

Table 5. The script and the description of the theatrical performance

$1^{\circ}$ Lara - Irene: Run
$2^{\circ}$ Tigers - Laura and Esther: They attack Lara
$1^{\circ}$ Lara - Irene: Attacks and defends
$3^{\circ}$ Dinosaur - Juan Carlos Sánchez: Follows Lara and
missteps
$1^{\circ}$ Lara - Irene: Takes the opportunity and shoots
$2^{\circ}$ Tigers - Laura and Esther: Attack again
$1^{\circ}$ Lara - Irene: She defends herself
$4^{\circ}$ Juan Carlos García-Ninja: Fights with Lara
$1^{\circ}$ Lara - Irene: She defends herself
$5^{\circ}$ thLoca - Cristina Martínez: Plays dumb and attacks
Lara $^{\circ}$ Lara - Irene: She defends herself
$6^{\circ}$ Butler 6th - Yolanda: Chases Lara
$1^{\circ}$ Lara - Irene: Lara shoots

The script of the play. Group 1 (Session 4)

The perfomance. Group 1 (Session 5)

Table 5 allows us to compare the script, elaborated in Session 4, and what happened in the performance during

Session 5. In the script, there are some actions such as attacking, shooting and so on which are very similar, 
although different characters present them. A series of successive actions is what is priority in this new kind of story. Neither the context nor the disequilibrium that appeared in oral narratives are present here.

\subsubsection{Video Game, Stories and Moral Education}

Violence and video games at school

Most of the time during Session 5 was dedicated to a discussion about violence. The example presented here will allow us to understand, through the analysis of a micro conversational narrative, how the violence present in the videogame and in the performance was addressed in class. It can be an example, among many, of how to introduce values' education in the classroom in relation to mass media.

Prior to the transcript we will discuss, there was a long conversation. The children were not aware of any violence in the game and their performance. The following are two micro transcription narratives, one of which is embedded in the other. The protagonists of the first are the teacher and the class group. The second is the expression of an individual experience. Both include the features that Herman (2009) requires in order to define a narrative text.

The first narrative is the introduction to the task: establishing a context, a series of actions and a disequilibrium: "Imagine that I come from another planet and I do not know what violence is and you have to tell me" (1). A girl (3) believes that violence is the abuse of women. The fact that the children laugh at this response gives an idea of how regularly they face violent contexts, usually presented by the Spanish media. Almost immediately after, violence focuses on personal experiences.

Transcript 5. How to introduce a discussion about violence in the classroom

1. Teacher: Well, + + VIOLENCE APPEARS. + + Let's see, one moment (.) + + Imagine that I come from another planet and I do not know what violence is and you have to tell me ::: (suggested by the researcher)

2. (...)

3. Girl: ++ Someone who abuses women ++

4. Children laugh (...)

(...)

The personal experience of one of the children is present in the second narrative. Violence appears in a context much more closer to the children, a football game (6). This narrative includes additional elements. Causal sentences are referred to the consequences of such violence. Children are fighting to get the ball (5). The teacher, who participated in the dialogue, insists on the consequences through questions $(8,11,13)$. She always places the subject in a specific context. The conclusion is a reflection about violence in general terms (17): "Violence, + + does it mean fighting with other people? ++". But the child is coming back to his own experiences; he does not seem to have heard the question and he expresses his own situation: (18) "and so I got a red card".

5. Jony: I was playing soccer with my brother and :.:: :.:: to the boy and I kicked the boy: "bang:.:.:" (he gets up and kicks his legs) (laughs)

6. Teacher: What's that?

7. Jony: To take the ball from him

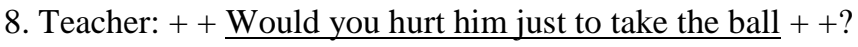

9. Child: Yes

10...

11. Teacher: Why?

12. Jony: Because ...

13. Teacher: + + Would you hurt him? ++

14. Child: Yes

15. Teacher: :::: Hurting is painful, right?

16. Child: Yes

17. Teacher: violence, ++ do you have to do something to hurt other people? ++

18. Child: And so I got a red card 
( ...)

It seems clear that violence must be posed in an environment close to children and from concrete situations. The conversation continued during that session and showed that the children clearly differentiated the violence of the game, and even when it is present during sleep, from real violence.

\section{Sharing reflections through the Internet}

We are in Session 6. This is the third part of the workshop, and we need to start working on the website, where children will share their experience with other people that are not present during the workshop: families, friends, etc. The last school year another group at the same school had already carried out a similar experience. We want to offer them a model to prepare their own Web site. One of the researchers will present the site. We will explore a long intervention of the research, much less experienced than the teacher at dialoguing with children. Here you will see another type of narrative, a monologue. Given the length of the intervention, the teacher interrupts to focus the attention of the children.

Once more, we will look at this narrative, considering the features proposed by Herman (2009). Firstly, a synthesis of the message that the researcher wants to transmit to the children is introduced (1). The context is marked by the protagonists and the main action: children of another class created a website the previous year. The temporal dimension is clear, marked especially by adverbs of time (and later, 3.1, 4, 5.2, 6.4) and expressed in past verb forms. The disequilibrium may be related to the fact that the researcher is going between specific pages of the Web site $(1.1,4,5.1)$ with no clear criteria. This could cause a conflict to the children that must be overcome in order to build their own representation of the task.

Transcript 6. The researcher's introduction to the Web site

1. Hector: This is the WEB PAGE that your school mates did last year(.)

1.1 Then::: in this first page what they did was to introduce themselves a little bit ::: who they were and what they had done during the workshop (.) (children laugh)

2. Teacher: S ... Silence ::::

3. Hector: they had been working about violence on TV and for that :::,. Why were people from a high school, FROM THIS SCHOOL

3.1. and then they put here also ::: its conclusions (.) of the workshop (.) are these (.) (he opens another page) and they are these ***

4 Teacher: Well, let's listen ++ we listen, then we have to do a website and now we need to listen otherwise we will not know + how to do it+

5. Hector: You can go to that other page. ++ On this page, as your high school classmates you were working in groups, and each person was responsible for one thing, (.) In small groups as :::

5.1 here you have four pages, each one as he had been done, with which group (.)

5.2 In this first what they did was that (.) They were reading about violence on TV, going out on the Internet, and then they said what they thought ::::::: about that and they wrote on this page $(* *)$ and then also they put drawings they had done (.) in the workshop :: ::

5.3 Before: that, they made some drawings and wrote some ideas as you have done (.) And then all these things are what we will put on the page (.)

5.4 then we return to this page and, from here, we go to another (.), Another group of students, what they did was to pick :::

Clearly, this narrative becomes a data source that can answer some research questions, namely why introducing the Internet from an experience with the media, in this case a video game. As in the past session, when they discussed about violence, children are situated in a concrete world, which here was the Web page that was made by other children from the same school.

\section{Main Conclusions: Epistemological Reflections}

In this paper, we have examined through an example how the narrative and analytical thinking (Buner, 1986; 2002) may be present in qualitative research looking for transcending the contraposition between different methodological approaches. To overcome, from a dialectical approach, the contraposition between different approximations, we should take into account the following aspects. In this paper, narrative is present as object and method of the research, complemented by a conceptual analysis. 
First, we look for an epistemological perspective that helps to overcome contradictions between positivist and interpretive approaches (Lincoln, et al., 2011). To do this we consider the contributions of Bruner (1986), even though at one point he proposed different criteria of truth for narrative and analysis. However, more recent work (2002, p. 101) seeks compatibility between these two modes of thought, even though their procedures are different. He states: "The narrative mode is existential and declarative", "the narrative one is normative and its mode subjunctive". It is more complex than jumping from one form to another, as he tells us that he had been looking for it for some time. In this work, we have started from a narrative approach and moved beyond a subjective interpretation, which served as a starting point.

Considering a conceptual perspective of analysis, software tools take on a relevant role. Through different stages of analysis, we construct a conceptual explanation of the data. Special attention is paid to ways in which Atlas.ti helps us to interpret data through successive levels; understanding what were processes generated in the workshop thus becomes easier. Individual activities and objects, as well as their educational value, are thus not examined as separate units of analysis, but within a systemic framework. Two levels of analysis were performed successively, all of them were subsequently combined, adopting a macro- and micro-analytical approach to the phenomena: 1) In the first phase of the analysis all the video-recorded sessions were segmented using Atlas.ti, in terms of the unit of their thematic conversational contents, and the participants' activities considered as a complete unit of meaning. In this context, the relationships between macro and micro levels of analysis were established. 2) In a second level of analysis, we elaborated concept networks, one of the most powerful features in Atlas.ti. This allowed us to deepen the relationships between the different sessions, adopting a macro-analytical level and, besides, in a micro-analytical sense, specific categories were defined as "codes" to classify specific segments of activity delimited in the first phase of our analysis. 3) Theoretically, the concept of narrative has been present in this work. If conceptual analysis focuses on what happens, a narrative approach allows to understand how and why specific phenomena take place. Stories are regarded as a cultural instrument, a form of discourse that can be both a subject and a research method (Hühn, Pier, Schmid \& Schönert, 2009a). If we look at the narrative as an object, we will see how the story has built workshop games and goals of the participants (Lacasa, Méndez, \& Martínez, 2008). In addition, the game also includes a story that children have in play or through the website. The new questions that now arise are related to thought and narrative discourse as a methodological tool in multiple disciplines. Hühn et al. (Hühn, et al., 2009b) and the recent updates through a living document amended in real time, which is something to consider moving forward.

In summary, we believe that many open questions arise from these three approaches and these will need to be answered in order to move forward. We propose to do this through concrete examples to better understand the real and virtual world, combining theories, methods and practices that transform the scenarios where human activity is generated.

\section{References}

Anderson, J. A. (2012). Media research methods: understanding metric and interpretive approaches. Los Angeles, Calif.: SAGE Publications.

Atkinson, P., \& Delamont, S. (2005). Analytic perspectives. In N. K. Denzin \& Y. S. Lincoln (Eds.), The SAGE handbook of qualitative research. Third Edition (pp. 821-840). Thousand Oaks, CA: Sage.

Bakhtin, M. M. (1925/1981). Forms of time and the chronotope in the novel. In M. Holquist (Ed.), The dialogic imagination (pp. 84-258). Austin, TX: University of Texas Press.

Brennen, B. (2013). Qualitative research methods for media studies. New York ; London: Routledge.

Bruner, J. (1986). Actual minds, possible words. Cambridge, Mass: Harvard University Press.

Bruner, J. (2002). Making stories. Law, literature, life. Cambridge, MA \& London, UK: Harvard University Press.

Chase, S. E. (2011). Narrative inquiry. Still a field in the making. In N. K. Denzin \& Y. S. Lincoln (Eds.), The SAGE handbook of qualitative research (4th ed., pp. 421-435). Thousand Oaks, Calif.; London: Sage Publications.

Davidson, J., \& Gregorio, S. d. (2011). Qualitative research and technology. In the midst of a revolution. In N. K. Denzin \& Y. S. Lincoln (Eds.), The SAGE handbook of qualitative research (4th ed., pp. 627-644). Thousand Oaks, Calif.; London: Sage Publications.

Denzin, N. K. (2010). Moments, Mixed Methods, and Paradigm Dialogs. Qualitative Inquiry, 16(6), 419-427.

Denzin, N. K., \& Lincoln, Y. S. (2011). Introduction: The discipline and practice of qualitative research. In N. K. 
Denzin \& Y. S. Lincoln (Eds.), The SAGE handbook of qualitative research (4th ed., pp. 1-21). Thousand Oaks, Calif.; London: Sage Publications.

Fludernik, M. (2009). Conversational narration/Oral narration. In P. Hühn, J. Pier, W. Schmid \& J. Schönert (Eds.), Handbook of narratology. Kindle Edition. New York: Walter de Gruyter Berlin.

Frasca, G. (2004). Videogames of the oppressed: Critical thinking, education, tolerance, and other trivial issues. In N. Wardrip-Fruin \& P. Harrigan (Eds.), First Person : New Media as Story, Performance, and Game (pp. 85-94). Massachusetts: MIT Press.

Gee, J. (2008). Video Games and Embodiment. Games and Culture, 3(3-4), 253-263.

Gee, J. P. (2006). Semiotic domains: Is playing video games a "waste of time"? In K. Salen \& E. Zimmerman (Eds.), The game design reader: A rules of play Anthology (pp. 228-267). Cambridge, Massachusetts: MIT Press.

Gee, J., \& Hayes, E. R. (2011). Learning and language in the digital age. New York: Routledge.

Georgakopoulou, A. (2007). Small stories, interaction and identities. Amsterdam ; Philadelphia: John Benjamins Pub. Co.,.

Hamera, J. (2011). Performance ethnography. In N. K. Denzin \& Y. S. Lincoln (Eds.), The SAGE handbook of qualitative research (4th ed., pp. 317-330). Thousand Oaks, Calif.; London: Sage Publications.

Herman, D. (2009). Basic elements of narrative (Kindle edition). Chichester, U.K. ; Malden, MA: Wiley-Blackwell.

Hollingsworth, S., \& Dybdahl, M. (2007). Talking to learn. The critical role of conversation in narrative inquiry. In D. J. Clandinin (Ed.), Handbook of narrative inquiry: mapping a methodology (pp. 146-176). Thousand Oaks, Calif. ; London: Sage Publications.

Holstein, J. A., \& Gabrium, J. F. (2011). The constructionist analysis of Interpretive practice. In N. K. Denzin \& Y. S. Lincoln (Eds.), The SAGE handbook of qualitative research (4th ed., pp. 341-358). Thousand Oaks, Calif. ; London: Sage Publications.

Hühn, P., Pier, J., Schmid, W., \& Schönert, J. (2009a). Handbook of narratology. New York: Walter de Gruyter Berlin.

Hühn, P., Pier, J., Schmid, W., \& Schönert, J. (2009b). The living handbook of narratology. http://hup.sub.uni-hamburg.de/lhn/index.php/Main_Page [view date: 17 Aug 2011]. New York: Walter de Gruyter Berlin.

Ivankova, N. V. (2013). Mixed methods applications in action research. London: SAGE.

Jenkins, H. (2006). Game design as narrative architecture. In K. Salen \& E. Zimmerman (Eds.), The game design reader: A rules of play Anthology (pp. 670-689). Cambridge, Massachusetts: MIT Press.

Jewitt, C. (Ed.). (2009). The Routledge handbook of multimodal analysis. London; New York: Routledge.

Juul, J. (2005). Half-real. Videogames between real rules and fictional worlds. Cambridge, MASS: The MIT Press.

Karnick, K. B., \& Jenkins, H. (1995). Classical Hollywood comedy. New York: Routledge.

Kemmis, S. (2008). Critical theory and participatory action research. In P. Reason \& H. Bradbury (Eds.), Handbook of Action Research. Second Edition (pp. 121-138). London, Thousand Hoaks: Sage.

Krippendorff, K. (2013). Content analysis : an introduction to its methodology (3rd ed.). Los Angeles ; London: SAGE.

Lacasa, P., Méndez, L., \& Martínez, R. (2008). Developing new literacies using commercial videogames as educational tools. Linguistics \& Education, 19(2), 85-106.

Lewins, A., \& Silver, C. (2007). Using software in qualitative research: a step-by-step guide. Los Angeles ; London: SAGE.

Lincoln, Y. S., Lynham, S. A., \& Guba, E. G. (2011). Paradigmatic controversies, contradictions, and emerging confluences, revisited. In N. K. Denzin \& Y. S. Lincoln (Eds.), The SAGE handbook of qualitative research (4th ed., pp. 97-128). Thousand Oaks, Calif.; London: Sage Publications.

Metz, C. (1974). Film language; a semiotics of the cinema. New York,: Oxford University Press. 
Meuter, N. (2009). Narration in Various http://www.lhn.uni-hamburg.de/article/narration-various-disciplines [view date: 05 Oct 2013]". In P. Hühn, J. Pier, W. Schmid \& J. Schönert (Eds.), The living andbook of narratology. http://www.lhn.uni-hamburg.de/ Hamburg: Hamburg University Press.

Murh, T., \& Friese, S. (2004). User's manual for Atlas.ti 5.0. 2nd Edition. Berlin: Scientific Software Development.

Murray, J. H. (2000). Hamlet on the Holodeck. The Future of Narratives in Cyberspace (3rd ed.). Cambridge, Mass: The MIT Press.

Pink, S. (2012). Advances in visual methodology. London; Los Angeles: Sage Publications.

Ryan, M. L. (2004). Narrative across media : the languages of storytelling. Lincoln: University of Nebraska Press.

Tedlock, B. (2011). Braiding narrative ethnography with memoir and creative nonfiction. In N. K. Denzin \& Y. S. Lincoln (Eds.), The SAGE handbook of qualitative research (4th ed., pp. 331-340). Thousand Oaks, Calif.; London: Sage Publications.

Tracy, S. J. (2013). Qualitative research methods: collecting evidence, crafting analysis, communicating impact. Chichester, West Sussex, UK: Wiley-Blackwell.

\section{(c) $\mathrm{BY}$}

This work is licensed under a Creative Commons Attribution 3.0 License. 